\title{
Transistor Width Size Effect on Voltage Drop and Improve Internal Resistance in CMOS Rectifier
}

\author{
Himshikha Sharma \\ M-Tech student \\ NRI Institute of Information Science and \\ Technology, Bhopal, M.P, India
}

\author{
Braj Bihari Soni \\ Assistant Professor \\ NRI Institute of Information Science and \\ Technology, Bhopal, M.P, India
}

\begin{abstract}
The proposed work based on the simulation studies for the effect of different width size of transistor on output voltage drop and internal resistance in CMOS rectifier. This paper presents the CMOS rectifier by using two PMOS and NMOS configuration and gives information about miniaturization technology. Hence, increase the width size from $4 \mu \mathrm{m}$ to $1100 \mu \mathrm{m}$ of PMOS and NMOS transistors. The results for $1100 \mu \mathrm{m}$ are $1.20 \mathrm{~V}$ is better than $750 \mu \mathrm{m}$ width size, and also minimize the internal resistance from $6.17 \Omega$ to $4.580 \Omega$ in CMOS rectifier. The model was designed and simulated using Microwind software and operated at a frequency of $50 \mathrm{~Hz}$ with an AC voltage source. A circuit was fabricated with $0.35 \mu \mathrm{m}$ CMOS technology.
\end{abstract}

\section{Keywords}

AC to DC converter, CMOS rectifier, width size of transistor, MOSFET internal resistance, low frequency. Voltage source.

\section{INTRODUCTION}

Recently, the most important technology is the miniaturization that has been increased in portable device at a large scale. It consists of several applications like transportation control, wireless network, automobiles identification. One of the main challenge for the researchers in layout designing is to reduce large voltage drop and high internal resistance. The researchers have paid attention towards the replacement of conventional rectifier which is more suitable as compare to it.

CMOS rectifier is one of the miniaturized technologies that have been proposed to replace the conventional rectifier due to having several applications. The conventional rectifier has a drawback of large voltage drop and high internal resistance. In CMOS technology, conventional rectifier and schottky diodes are not well suited, because these are not compatible with the CMOS technology. Then researchers searched a method to replace the converter by using CMOS rectifier which has lower voltage drop and low internal resistance form to the previous design. The electronic device which flows in one direction and used to convert the $\mathrm{AC}$ voltage to $\mathrm{DC}$ voltage is known as rectifier. The process is called rectification. It consists of PN junction diodes. Due to having

large numbers of applications, CMOS rectifier are useful in many different areas such as wireless network, biomedical, radio frequency identification communication area electronic portable devices like smart phones, laptops etc.

\section{PROPOSED CMOS RECTIFIER}

Generally, the conventional rectifiers are constructed by using diodes. But the diodes have not required for low voltage circuits and power loss is very large. Therefore, CMOS rectifier in now used because it solved all problems and reduces the forward voltage drop. The CMOS rectifier structure are simple which consist of two PMOS and NMOS transistors, is shown in the Figure 1. In this Figure M1 and M3 are PMOS transistors and M2 and M4 are NMOS transistors. For each cycle, one PMOS and NMOS will turn $\mathrm{ON}$. The CMOS rectifier is used to convert a pure sinusoidal input waveforms having at a frequency of $50 \mathrm{~Hz}$ and load resistance of $2 \mathrm{~K} \Omega$. This larger value of load resistance increases the efficiency of CMOS rectifier. It works at a very low input voltage at $0.25 \mathrm{~V}$.

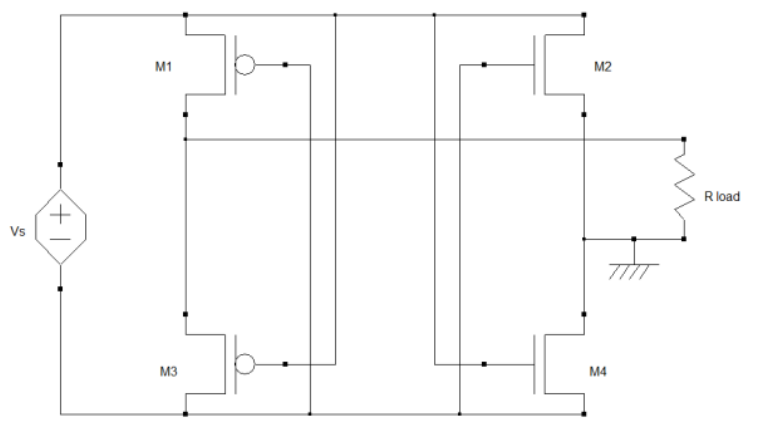

Figure.1 CMOS rectifier circuit

Although these CMOS rectifier structure are simple, By using $0.35 \mu \mathrm{m}$ CMOS technology. This rectifier used to convert input sinusoidal wave from negative half waves into positive, which is possible with two PMOS and two NMOS transistors shown in figure 1 . Hence, the voltage drop can be minimized by using large size of transistors to decrease the resistance and get a small voltage drop.

The circuit was simulated with Microwind software. The voltage efficiency is defined as the fraction of the DC output voltage $V_{\text {out }}$ and the $A C$ input voltage amplitude $\left|V_{\text {in }}\right|$. The efficiency of output voltage is higher with larger load resistors in CMOS rectifier. Generally the circuit cannot work when the input voltage is larger. So, in this paper we design CMOS rectifier to overcome these drawbacks. This rectifier work at a $1.5 \mathrm{~V}$ at input voltage.

The main goals of this paper are the reduction of the voltage drop and internal resistance over the CMOS rectifier and achievement of a high efficiency. In this analysis reduce voltage drop and power loss from CMOS rectifier to the load resistor. It follows the change of the size of the MOS transistor, as the size increase, the channel resistance will become small. The voltage drop on the channel resistor will less, hence this will increase the output voltage $\mathrm{V}_{\text {OUT }}$. 


\section{DIFFERENT PARAMETERS}

For every positive cycle and negative cycle of the input AC voltage in PMOS and NMOS transistors have the internal resistance. In CMOS rectifier, when the width size of PMOS and NMOS transistors width size are increase then the total resistance is reduced. It proves that the width size is one of the factors that effect on the internal resistance and voltage drop. The transistor larger width size make the bigger current to go through to the transistor, hence it have the small value of the resistance. The width over length ratio for transistor is 750/1. The CMOS rectifier has lower internal resistance by considering the capability of electron mobility in PMOS and NMOS transistors.

\subsection{Analysis of width size of transistor on internal resistance in CMOS rectifier}

In this analysis, all transistor width size is set to be similar. The designs are varied from small, medium and large width sizes. Thus, the width size of PMOS and NMOS transistor is varied to improve the drive current and reduce the internal resistance in the circuit. The width size of PMOS and NMOS transistor is enlarged from $4 \mu \mathrm{m}$ to $1100 \mu \mathrm{m}$ while the length size of PMOS and NMOS transistor is set at $1 \mu \mathrm{m}$. These analysis are done to get the lower internal resistance from $6.17 \Omega$ to $4.580 \Omega$.

\subsection{Analysis on the width size of the transistor to the output voltage in CMOS rectifier}

The focused on this design is to determine the output voltage using $1100 \mu \mathrm{m}$ large width size of transistor is better than $750 \mu \mathrm{m}$ small width size of transistor. It means that the bigger width gives better output voltage $1.20 \mathrm{~V}$ compared to lower width gives $0.61 \mathrm{~V}$.

\subsection{Analysis of Power Conversion Efficiency dependence on transistor sizing}

This analysis shows PCE dependence on the width size of transistor. The wider version exhibits a slightly larger peak PCE, where width size of PMOS and NMOS transistor is varied from lower to higher. PCE of the rectifier is defined by output power $\mathrm{P}_{\mathrm{OUT}}$ divided by the input power $\mathrm{P}_{\mathrm{IN}}$. The sum of the output power and the loss of the rectifier is define the total input power. PCE can be written as:

$\mathrm{PCE}=\mathrm{P}_{\mathrm{OUT}} / \mathrm{P}_{\mathrm{IN}}$

$\mathrm{PCE}=\mathrm{P}_{\text {OUT }} /\left(\mathrm{P}_{\text {OUT }}+\mathrm{P}_{\mathrm{LOSS}}\right)$

\section{SIMULATION RESULTS AND DISCUSSION}

From the CMOS rectifier design, the effect of width size was studied. Three different values of width were set in this study at $4 \mu \mathrm{m}, 750 \mu \mathrm{m}$ and $1100 \mu \mathrm{m}$. The length of PMOS and NMOS transistors is set constant at $1 \mu \mathrm{m}$ to determine the effect of the width. Hence, the output waveform was analyzed. For every positive and negative cycle of the input voltage, the transistors will represent as diodes which have the internal resistance. In table 1 shows the PMOS and NMOS different width sizes. For the analysis of similar width size $4 \mu \mathrm{m}$ of transistor, design 1 have the very large internal resistance at $1570.00 \Omega$ and the maximum output voltage is only about $15 \mathrm{mV}$ lower compared to the input voltage. A slight delay can be observed of about 5 ns. This delay can be reduced by increasing the width size of PMOS and NMOS transistor. The main aspects of rectifier are the maximum output voltages which can be reached at $1.21 \mathrm{~V}$, and for the study of enlarging the transistor width size, design 3 have the total resistance at $4.580 \Omega$ compared to $6.170 \Omega$ for design 2 .

Table 1. Output voltage and Total Internal Resistance for similar width size in CMOS rectifier

\begin{tabular}{|c|c|c|c|}
\hline Design & $\begin{array}{c}\text { Design of CMOS } \\
\text { rectifier } \\
\text { (PMOS/NMOS) }\end{array}$ & $\begin{array}{c}\text { Total } \\
\text { Internal } \\
\text { Resistance }\end{array}$ & $\begin{array}{c}\text { Output } \\
\text { Voltage }\end{array}$ \\
\hline 1 & $4 \mu \mathrm{m} / 4 \mu \mathrm{m}$ & $1570.00 \Omega$ & $15 \mathrm{mV}$ \\
\hline 2 & $750 \mu \mathrm{m} / 750 \mu \mathrm{m}$ & $6.170 \Omega$ & $0.61 \mathrm{~V}$ \\
\hline 3 & $1100 \mu \mathrm{m} / 1100 \mu \mathrm{m}$ & $4.580 \Omega$ & $1.20 \mathrm{~V}$ \\
\hline
\end{tabular}

The simulation results of CMOS rectifier circuit will be shown below. The output voltage could reach $1.20 \mathrm{~V}$. However the structure, which helps to reduce the voltage drop, power loss and minimize internal resistance. Also reduce the chip area in MOSFET. The input voltage is set to $1.5 \mathrm{~V}$ at the voltage source and the sine waveform carrier frequency is decided to be $50 \mathrm{~Hz}$, the phase degree is 180 and the amplitude is $0.25 \mathrm{~V}$. The load resistor is set to $2 \mathrm{~K} \Omega$ in the CMOS rectifier circuit and the value of the internal resistance is obtained.

Three different design configurations are analyzed. The width size of PMOS and NMOS is set to be similar and varied from $4 \mu \mathrm{m}$ to $1100 \mu \mathrm{m}$. For the first design configuration, the width size of transistor is $4 \mu \mathrm{m}$. In the second design configurations, the width size is varied up to $750 \mu \mathrm{m}$ and third design configurations; the width size of transistor is varied up to $1100 \mu \mathrm{m}$. This analysis is done to observe the variation of output voltage and overcome the voltage drop. A CMOS rectifier using $0.35 \mu \mathrm{m}$ technology was implemented using Microwind/DSCH Tool software.

Figure 2 shows the output current and voltage waveforms of the CMOS circuit from the simulation taken using $1100 \mu \mathrm{m}$. From figure follow the change of the size of the PMOS and NMOS transistor, as the width size increase, the voltage drop on the resistor will less and internal resistance will become small. Hence this will increase the output voltage $\mathrm{V}_{\text {OUT. }}$. In Figure 2 shows that when the width size of the PMOS and NMOS transistors is $\mathrm{w}=1100 \mu \mathrm{m}$, output voltage $=1.20 \mathrm{~V}$, but when the width size of the MOS transistor is $\mathrm{w}=750 \mu \mathrm{m}$, output voltage $=0.61 \mathrm{~V}$. Therefore as the width size of the MOS transistor increases, the voltage drop on the whole will decrease and the value of output voltage is relatively high. 
Figure 1(b): Voltage, Current vs Time when $w=1100 \mu m$

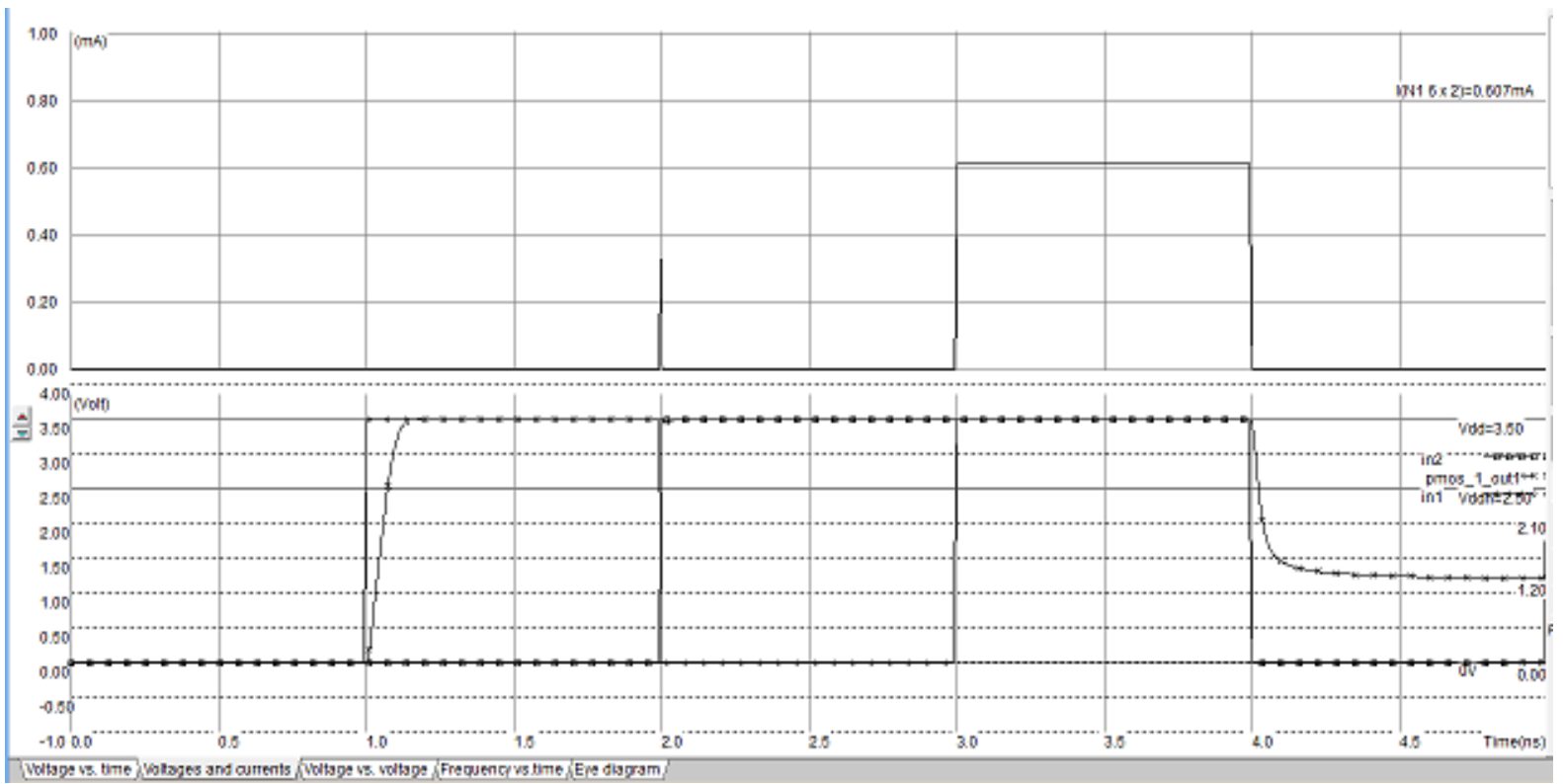

Table 2. Total Internal resistance at $1100 \mu \mathrm{m}$ width size

\begin{tabular}{|l|c|c|}
\hline Paper & Width Size & Internal Resistance \\
\hline Base Paper & $1100 \mu \mathrm{m}$ & $5.80 \Omega$ \\
\hline Proposed Paper & $1100 \mu \mathrm{m}$ & $4.580 \Omega$ \\
\hline
\end{tabular}

Table 2.Represents the difference between the internal resistances obtained from the base paper and proposed paper at a constant width size about $1100 \mu \mathrm{m}$. In the base paper, the internal resistance is $5.80 \Omega$ at $1100 \mu \mathrm{m}$ width size of PMOS transistor. The proposed work has less internal resistance at the $1100 \mu \mathrm{m}$ width size of the transistor.

\section{CONCLUSION \& FUTURE SCOPE}

Based on the analysis the paper has proposed a very less voltage drop from the variation in the width size of transistor and minimization of the internal resistance in the CMOS rectifier. The simulation results is to determine the low Voltage drop and reduce internal resistance in CMOS rectifier. The variation in the width size of the transistors will affect the internal resistance and output voltage drop on the performance of the CMOS rectifier. By using $1100 \mu \mathrm{m}$ of width gives better output voltage which is $1.20 \mathrm{~V}$ as compared to $750 \mu \mathrm{m}$ width which has $0.61 \mathrm{~V}$. The smaller width size of the transistor resulted in the large voltage drop in CMOS rectifier. An increase in the width size of the transistor is reducing the voltage drop. Since it has optimum output performance and low internal resistance, A future aspect will be focused on the best circuit design in CMOS rectifier design.

\section{ACKNOWLEDGEMENT}

Author would like to thank NIIST Bhopal College for providing Simulation software to carry out thesis work and their valuable guidance from time to time.

\section{REFERENCES}

[1] M.A. Ab Raop, R. Radzaun, M.K. Humzah,.;Rahimi M.K.M.S.,"CADENCE Simulation on the Effect of Transistor Width Size on Internal Resistance in CMOS rectifier Using Two PMOS and NMOS" in IEEE , 2013 (ISIEA 2013), pp. 144-147.

[2] M.A. Ab Raop, R. Radzaun, M.K. Humzah, Rahimi.M. K. M. S., "Investigation of different width size of transistor on internal resistance and output power in CMOS rectifier using two PMOS and NMOS" in IEEE, 2013 (SCOReD), pp. 417-420.

[3] Ab Roap M. A.; Radzaun R.; Humzah,M. K.; Rahimi M. K. M. S.," Effect of different widths in CMOS rectifier for low voltage and frequency application" in IEEE, 2012 (ISCAIE 2012), pp.26-28.

[4] K. Kotani and T. Ito, "High efficiency CMOS rectifier circuits for UHF RFIDs using Vth cancellation techniques," in ASIC, 2009. ASICON '09. IEEE 8th International Conference on, 2009, pp. 549-552

[5] Peters C.; Kessling O.; Henrici F.; Ortmanns M.; Manoli Y. "CMOS integrated highly efficient full wave rectifier" in IEEE, 2007, pp. 2415-2018.

[6] R. Yuan and D. P. Arnold, "Input-powered energy harvesting interface circuits with zero standby power," in Applied Power Electronics Conference and Exposition (APEC), 2011 Twenty-Sixth Annual IEEE, 2011, pp. 1992-1999.

[7] A. S. W. Man, E. S. Zhang, H. T. Chan, V. K. N. Lau, C. Y. Tsui, and H.C. Luong, "Design and Implementation of a Low-power Baseband system for RFID Tag," in Circuits and Systems, 2007. ISCAS 2007. IEEE International Symposium on, 2007, pp. 1585-1588

[8] Y. Yuan, S. Yin, and F. F. Dai, "A novel low-power input-independent MOS AC/DC charge pump," in Circuits and Systems, 2005. ISCAS 2005. IEEE International Symposium on, 2005, pp. 380-383 Vol. 1. 
[9] Qiang Li, J.Wang and Y.Inoue, “A two stage CMOS integrated highly efficient rectifier for vibration energy harvesting application” 2014, JICEE Vol. 4 pp336-340.

[10] F.Jiang, D. Guo, L. L. Cheng. "Analysis and design of power generator on passive RFID transponders" Progress in Electromagnetics Research Symposiwm, Hangzhou, China, March 2008.

\section{AUTHORS PROFILE}

Himshikha Sharma has received her B.Tech degree in Electronics and Communication Engineering from Alpine Institute of Technology, Ujjain (M.P.). At present she is pursuing M.Tech in VLSI Design and Embedded System. Her area of interest includes low power VLSI design, Embedded systems.

Braj Bihari Soni is working as Assistant Professor in NRI Institute of Information Science and Technology, Bhopal (M.P.).He has received his Bachelor of Technology from Nagaji Institute of Technology and Management, Gwalior, (M.P) and M.Tech degree from NRI Institute of Information Science and Technology, Bhopal, (M.P). 